Open Scientist Handbook • OSH

\title{
Beyond the Workshop: better or never?
}

Bruce R. Caron

Published on: Mar 10, 2021

DOI: $10.21428 / 8 b b b 7 f 85.2 e 47 d 716$

License: Creative Commons Attribution 4.0 International License (CC-BY 4.0). 


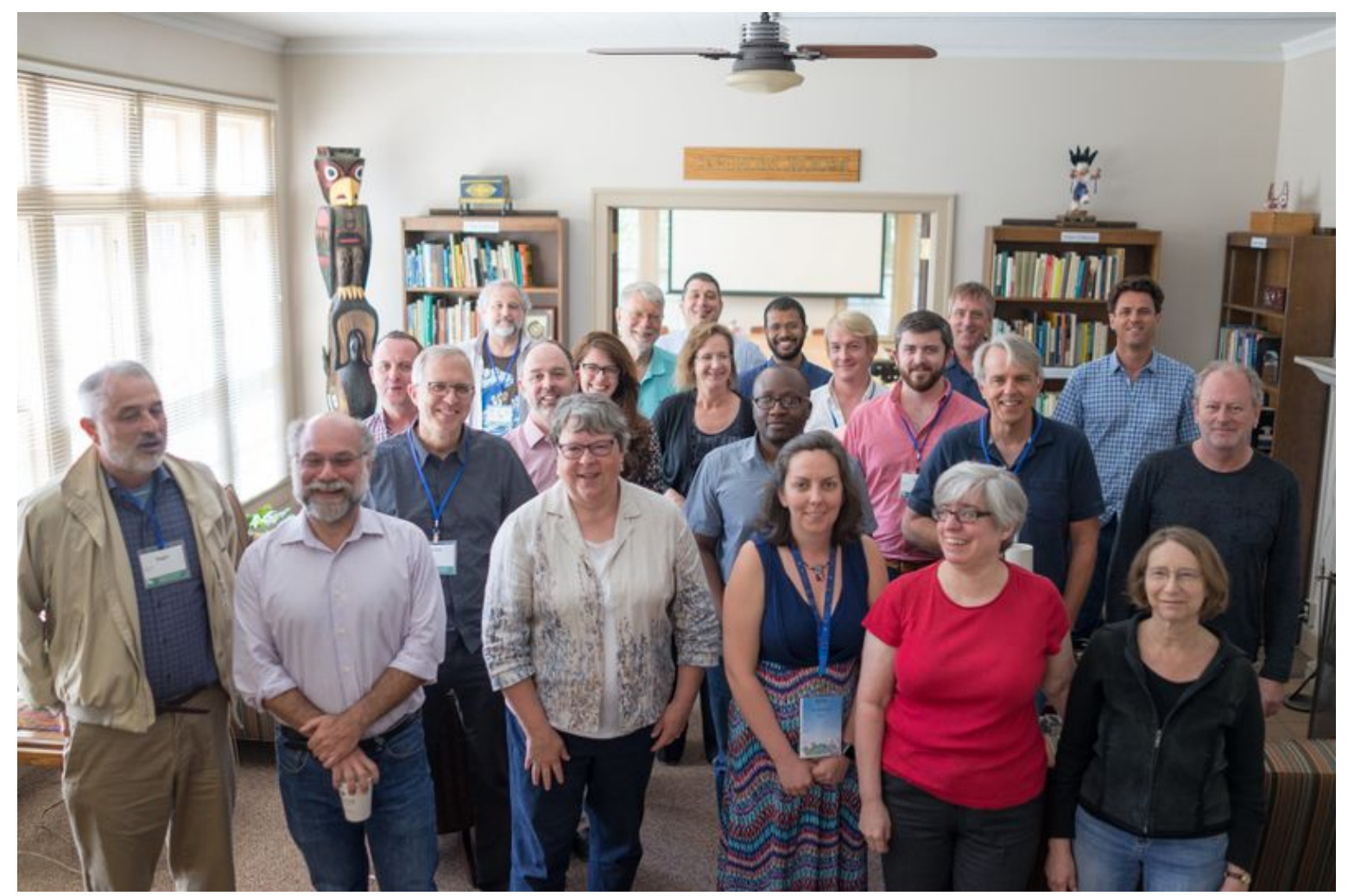

Commoners workshopping

\section{Workshops demonstrate how much science needs shared knowing.}

There are lots of reasons to not run workshops, and a few reasons why these can be uniquely instrumental. The best workshops represent a mode of in-person shared knowing sometimes known as BORPSAT: A Bunch of the Right People Sitting at the Table.

If you can...:

- Know who the right people are;

- Know how to contact them and get them on a plane on the same weekend;

- Know how to facilitate the conversations necessary to draw out their variety of knowing (Knowing and conversation);

- Know how to record this and where to share it; and,

- Will foster after-connections among the workshop members (without funding, of course);

Then you've got what you need to run a great workshop. 
Workshops can be effective for synthesizing new ideas and tackling common pain points. They are expensive (in many ways), and often unnecessary. If the "right people" have other venues to meet each other and have acquired enough inter-personal trust to open up remotely, then they are ready to "gather" on the internet/teleconference.

\section{The NSF and NIH each spent a billion dollars funding science workshops last year, and all you got was a lousy white-paper.}

Significant scientific funding and scientist participation in collectives can already be evidenced in the activity of hosting scientific workshops to address important, shared issues. Science workshops are a major current expression of the value and need for science collectives. Workshops are where scientists gather in place to collectively respond to challenges they face in their research. In the future, open collaborative networks will be able to spin off virtual workshops on the internet at any time without additional funding. Today, workshops are the $20^{\text {th }}$ Century model of how to gather to solve mutual complex problems.

It is likely that you have travelled to and participated one or more workshops over the past decade. You've met a lot of really smart people. Shared gallons of really bad coffee. Had more than a few beers after long, long days of somewhat-facilitated work. You have spent considerable time helping write reports and white-papers. Most of these papers you never saw again. A few got published. Some workshops are more successful. Some are a shambles. As a mode of collective science, there are times when a workshop makes perfect sense, and maybe always will.

\section{Workshop worries}

There is also a way-and good reasons-to make the great majority of workshops unnecessary, by funding and building science communities instead. Just as digital journal articles have acquired their granularity and an arbitrary scarcity based on the history of printed journals, workshops have acquired their own granularity and scarcity. Here are some of their limits:

- Workshops need to have enough "work" to do to fill 1-1/2 to 2 days of effort (to justify 2 days of travel). You can't do a half-day or, say, a twenty-day workshop;

- Workshops need to support say 16-34 participants, and these scientists must be available at the same time;

- Workshops get funded to explore science research topics "important" enough to justify their $\$ 40 \mathrm{k}$ budget. Other collective issues and needs are not currently very fundable. 
- Workshops need to have a topic that is still an issue months after the proposal submission.

- Workshops require moving people around in airplanes.

- Some fraction of workshop proposals don't get funded at all.

Workshops are a product of Twentieth Century science. Science before the internet. Science before someone figured out how to let scientists create their own collectives online at virtually no cost.

That's right NSF and NIH funders; there is a way you can support thousands of selforganized online workshops with a net marginal cost of zero. Well... zero, that is, after investing about $20 \%$ of the current outlay for workshops to support several dozen selfmanaged science communities.

Above, we explored a working model for this Twenty-First Century strategy, building a commons with online collaborative networks. We have lessons already learned and ready to be copied across other research domains; a model that already supports better, more effective, and more nimble collectives than the current workshop model. That being said, you might be in a position (funded) to do a workshop. So do are really great one, where the knowing conversations flow.

\section{Ten rules for a better workshop}

An open-science workshop takes demand sharing and fierce equality into a two-day converse-a-thon, where every participant gets their say, and the entire room moves at the speed of conversation.

\section{Here is the Santa Barbara Workshop model:}

This is a time-tested model for getting the people-in-the-room to explore all of their expertise and their imaginations. It works every participant to their limit. The feedback most received from these workshops: "I've just worked harder and I've also had more fun than I have ever experienced before at any workshop." At the end, people actually complain of "brain fatigue," a condition you help cure with beer, or a good walk on the beach (it was born in Santa Barbara, after all). If you don't have a beach, then an uptown walk also works. 


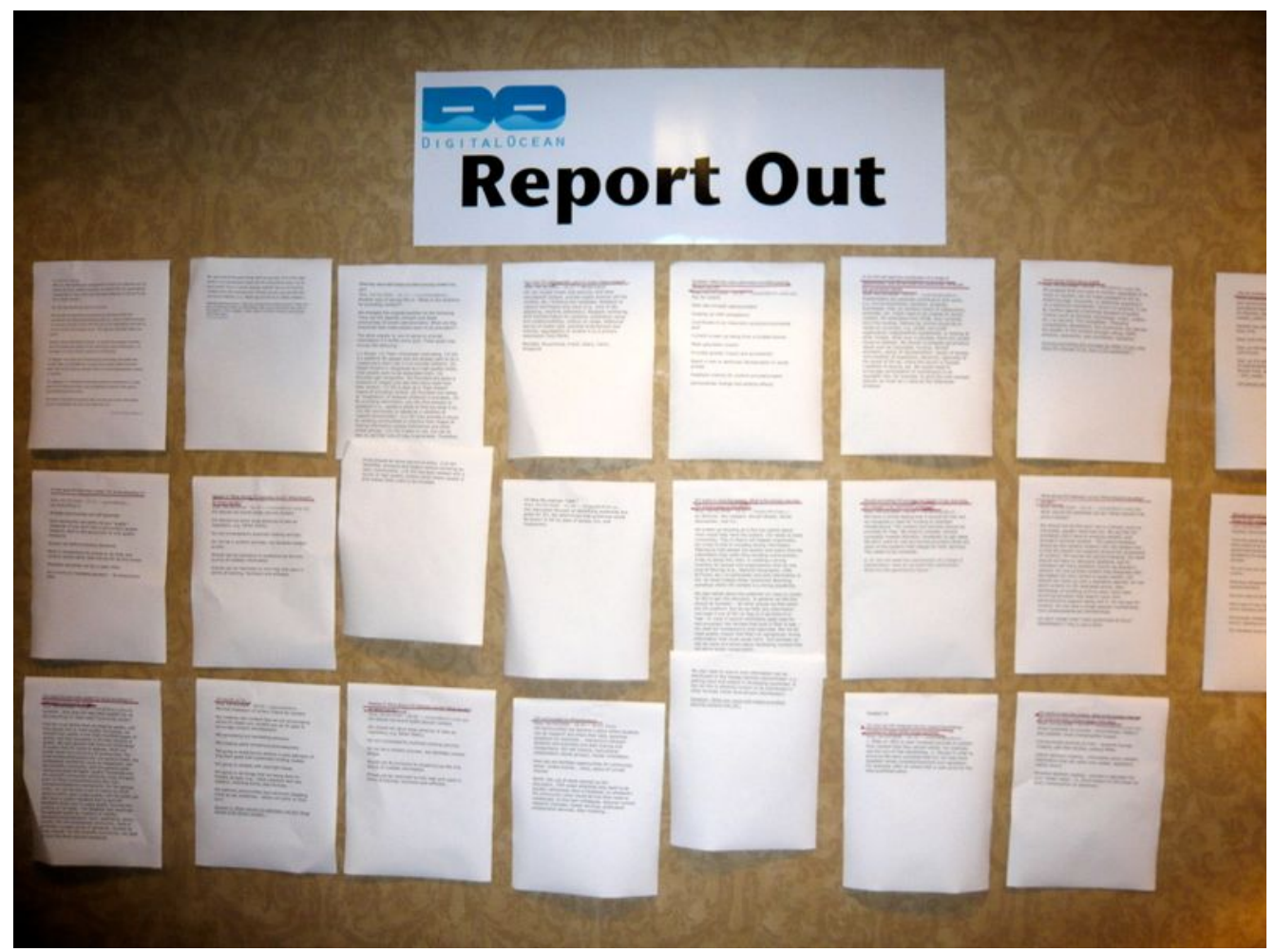

If you are interested in doing your own Santa Barbara Workshop, you can use these 10 rules to facilitate the best workshop you've ever done:

\section{RULE 1: Pick a place that's right in town and give them dinner/lunch}

Before the workshop starts, make sure you feed the participants. Pick a downtown hotel near cafes and bars. Never do this at an airport hotel, or isolated venue. If your workshop starts after lunch, feed them a good lunch first. If your workshop starts in the morning, feed them dinner the previous night. But do not try to gather them for breakfast before the workshop. People have a variety of breakfast desires. Have a table with coffee and snacks in the room.

\section{RULE 2: The ideas need to travel at the speed of conversation}

No more than 35/36 people. Small groups all day.

The workshop planning should focus on getting a wide spread of expertise in the room, but no more than about 35 people ( 7 tables of five, or 5 tables of 7 , or 6 tables of 6 ). The whole day will be used to promote critical conversations at these tables. As soon as the conversation lags at a table, give it something new to do (e.g., another question [see \#4 below]). 


\section{RULE 3: Open with a blue sky session, get the creative juices going}

Start the conversations with a real "blue-sky" design problem. Let everyone add their fantasy to the solution of a problem. Give them paper and markers, scissors and glue. Give them props and tape. This is the only session where there is a brief report out. Let the groups compete for the most fantastic solution. Have them map their ideas on big Post-its and then stick these on the walls of the room. This beginning session is designed to help the group achieve an open conversational mode of interaction.

\section{RULE 4: Give them real questions to answer, and let them add to these}

After the blue-sky exercise, each table is given a question to tackle (not necessarily the same question, although most tables might end up answering every question). In the weeks before the workshop, spend real time coming up with 10-12 key questions. Map out how the answers to these add up to a larger picture. Rank these questions as "central" or "if time allows". Create some colored sheets of paper that say "Hot Topic" on them. Give each table a few and encourage people to create their own question. Give these questions to OTHER TABLES. Never let someone answer their own question. Some questions will be better answered by tables with specific expertise, others by tables of mixed expertise (see below). Credit: This rule was provided by Susan Colitan, Vice President of the Paul G. Allen Family Foundation. The better the questions the more knowledge you will extract from the workshop!

\section{RULE 5: Break up groups 2-3 times over the course of the day and vote with your feet}

Give each member a name tag (first NAME on both sides). This tag should also tell them which table at which to sit (designated by color, number, animal, etc.). You might want to start by mixing up the expertise at each table. For example the COLOR designated tables might include a technical expert, a managerial expert, some content domain specialists, and others. After a couple hours, have everyone switch to the NUMBER table, which might be grouped by expertise. Later, they might switch to an ANIMAL table, etc. At the end of the day have a final question back at the original table. At any time anyone can move to a different table. This is called "voting with your feet." Announce this at the beginning and also every time your swap out table designations.

\section{RULE 6: Use big paper Post-its to gather ideas}

The table conversations need to be captured first on big Post-its. Have the table choose a recorder. All comments are written down. This means that each person's contribution 
is captured and made visual for the table. Do not simply write these on a computer. Sometimes the person who made the comment will want to revise this, or expand on it. Sometimes the recorder will not understand the comment, and will ask for clarification. Everyone's voice is heard in this process. The conversation moves as fast as people can talk. When silence breaks out, the facilitator will come by to ask if the table needs another question.

\section{RULE 7: Create narratives from the Post-its and put these online immediately}

Have a volunteer at each table who merges the contents of the big Post-its into a narrative. This narrative might be one paragraph, or several. You can capture these narratives in any way that works for you. Google documents, shared Dropbox: whatever you are most familiar with. The Post-its and these narratives are the output from the meeting. They are the gold you have woven from the ideas of your participants. It is tempting to skip the Post-it and go right to a computer. Do not allow this. The Post-it step is there to keep the conversation flowing and the let each person know their ideas are being captured.

\section{RULE 8: Many conversations in one room}

Workshop planners often make the mistake of having a plenary room and then breakouts in separate rooms. Set up the main room in round tables; all the conversations will happen there. It will get loud, but people will also gain energy from the buzz in the room. And when they are voting with their feet, they only need to meander to another table and join the conversation.

\section{RULE 9: No long introductions. No formal report-outs, but quick checks. No breaks, break anytime}

At the start, have each person stand and say their name. Then have them give three words that express their hopes for the day. This should take only 10 minutes. During the course of the day, have a volunteer print out the narratives from the tables and post them on the wall near the coffee in real time. Let the display of these become an ongoing marker of the accomplishments of the workshop.

Do not have any special report-out breaks, this only slows down the conversation. Do not schedule coffee or other breaks (except for lunch if you started in the morning), but encourage everyone to take a break any time they feel like it. They can get coffee, walk around the block, and do whatever they need to gather their attention back to the workshop. Once an hour, the facilitator will do a quick check-in with the room. Stop the 
conversations briefly to ask if there are any concerns about the process, and remind people to go look at the report-out wall. Arrange a good lunch for everyone.

\section{RULE 10: Facilitator keeps the conversation going}

The Santa Barbara Workshop is a fast-moving symphony of conversations and inspirations. The key is to keep the ideas flowing, capture these as effectively as possible, and support each table with a supply of questions and a recording mechanism. The main facilitator will walk among the tables ready to supply a new question, or to gather the "hot topic" questions for other tables to answer. The facilitator will also decide when to rotate the tables, and can help keep the process on track.

At the end of the day, be prepared for the participants to be excited and exhausted. They will feel like their ideas have been heard, and their contributions have been saved. When they browse the report-out display, they will see how their table's answer to the questions exposed different solutions from those of other tables. They may want to be alone after eight hours of constant conversation. They might be ready for some beer.

At the end of the day, you will likely have a document that is hundreds of pages long, with multiple insights into the key questions that your organization faces. You will have mined the best ideas from 35 people. And these 35 people will leave the workshop satisfied that their time and their expertise has been well used and honored. 


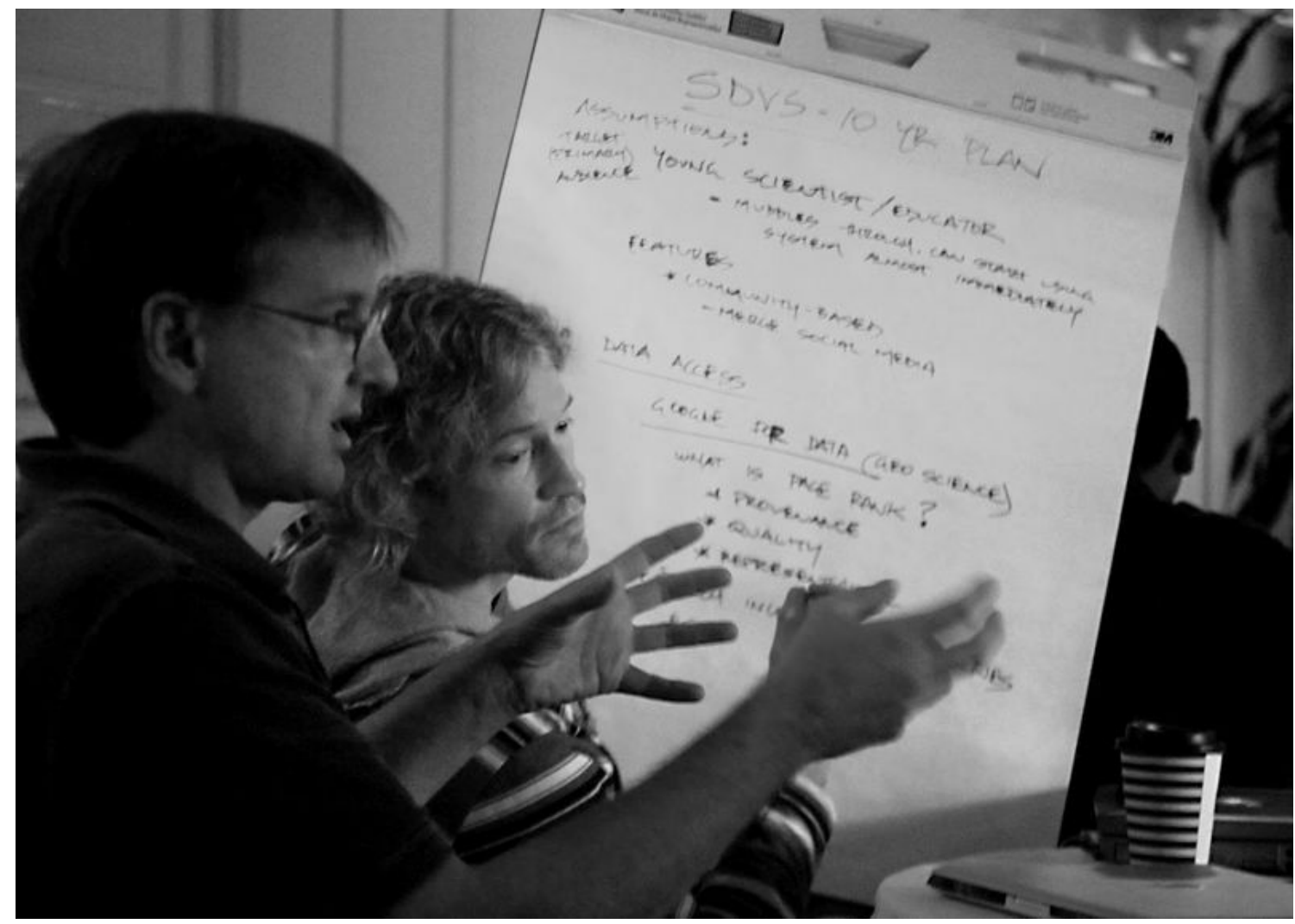

\section{My brain hurts}

The Santa Barbara workshop can be used for a wide range of planning and design problems. You can do "mini-workshops" with two or three tables. There are other similar styles of workshop, you can look them up on the web. When you ask anyone who has participated in this type of workshop, they will tell you how much fun they had getting their brains picked clean. They might also note that other workshops, where they are forced to watch PPTs in a room with 100 others, and then raise their hands one-by-one to speak, now seem boring and inefficient. This is the downside of the Santa Barbara Workshop: once you've gone there, you can never go back.

\section{Bibliography: Oppen Scientist Handbook References}

